\title{
Application of Smooth Blasting in Yazhugou Tunnel
}

\author{
Xiaolin Wang ${ }^{1}$ and Wei Yin ${ }^{2 *}$ \\ ${ }^{1}$ School of Civil and Environmental Engineering, City College of Southwest University of Science and Technology, Mianyang, Sichuan, \\ 621000, China \\ ${ }^{2}$ China Railway 20 Bureau Group Third Engineering Co., Ltd, Chongqing, 400000, China
}

\begin{abstract}
This paper takes Yazhugou Tunnel, a highway project in the upper reaches of the Yalong River as the example to summarize the application of smooth blasting in the Yazhugou Tunnel from the aspects of the feasibility, resource allocation, blasting parameters, drilling and blasting technology and the guarantee measures, with the construction characteristics of the tunnel blasting, the type of surrounding rocks, construction technology and cost taken into consideration.
\end{abstract}

\section{Introduction}

Blasting control plays an important role in the over-under-break during the construction of highway tunnels. Due to the influence of surrounding rock type, construction technology and cost, the constructor tends to choose different excavation techniques. This paper illustrates the feasibility and construction calculation by taking the excavation of the Yazhugou Tunnel as the example.

\section{Project Overview}

The Yazhugou Tunnel is located at the B-mark between the Youlaxi Ditch and Yazhu Ditch, and it is on the traffic reconstruction road of the upstream hydropower station on the Yalong River. The mileage of the Yajiang end is K103+490, and that of the Xinlong end is K104+662.

The bedrock of the Yazhugou Tunnel entrance is Triassic-Yajiang strongly-withered weakly-withered metamorphic stone plate mixed with sand. It is bare and relatively broken, with strong unloading looseness and a fragmented mosaic structure. Its strong unloading depth is $40 \sim 50 \mathrm{~m}$, and the weak one is $90 \sim 110 \mathrm{~m}$. The entrance is covered by $2 \sim 4 \mathrm{~m}$ thick Quaternary Holocene landslide gravel soil, which is mainly composed of metamorphic fine sandstone and slate; the underlying bedrock is Triassic-Yajiang metamorphic stone plate mixed with sand. It is bare and relatively broken, with strong unloading looseness and a fragmented mosaic structure. The surrounding rock of $\mathrm{K} 103+660.00 \sim \mathrm{K} 103+920.00$ is Triassic-Yajiang metamorphic stone plate mixed with a small amount of sand. It is relatively intact and mildly weathered with a medium-thick layered structure. The section of $\mathrm{K} 103+920.00 \sim \mathrm{K} 104+170.00$ is Triassic-Yajiang thin sandy plate mixed with an extremely small amount of medium-thick metamorphic stone. The rock mass is relatively fragmented and slightly weathered. The K104+170.0 K104+305.00 section is Triassic-Yajiang metamorphic stone plate mixed with a small amount of sand. The rock mass is relatively intact and slightly withered with a medium-thick layered structure. The $\mathrm{K} 104+305.00 \sim \mathrm{K} 104+530.00$ section is Triassic-Yajiang weakly-weathered metamorphic stone plate mixed with sand. It is relatively broken, with strong unloading looseness and a fragmented mosaic structure. Its strong unloading depth is $40 \sim 50 \mathrm{~m}$, and the weak one is 90-110m.

\section{Feasibility of smooth blasting}

\subsection{Economic considerations}

Due to the remote location, it is difficult to access large tunnel equipment and is costly to use it. It is possible and more convenient to acquire explosive warehouses of other construction units.

\subsection{Operability}

As a more mature construction process, smooth blasting requires lower level of technical workers, and it has strong actual operability.

\subsection{Advantages}

Compared with ordinary blasting, smooth blasting delivers is more regular shapes, therefore, it is more effective in utilizing the space. Smooth blasting also disturbs a smaller range of surrounding rocks and causes lesser cracks, which can effectively reduce the landslide caused by stress concentration. In addition, it can reduce rock-fall and dangerous section, and shorten the time of danger removal and processing. It also helps to save

"Corresponding author's e-mail:2Yinwe8609@163.com 
materials, reduce engineering cost, and use blast-holes more efficiently.

\section{Personnel and mechanical equipment}

\subsection{Staff}

Table1. Construction staffs.

\begin{tabular}{|c|c|c|}
\hline Constructor & Quantity & Duty \\
\hline $\begin{array}{l}\text { Operation } \\
\text { leader }\end{array}$ & 1 & $\begin{array}{l}\text { Responsible for overall } \\
\text { arrangement }\end{array}$ \\
\hline Dispatcher & 1 & $\begin{array}{l}\text { Responsible for overall } \\
\text { construction process coordination }\end{array}$ \\
\hline $\begin{array}{l}\text { Technical } \\
\text { director }\end{array}$ & 1 & $\begin{array}{l}\text { Assist project technicians to solve } \\
\text { technical problems }\end{array}$ \\
\hline $\begin{array}{l}\text { Quality } \\
\text { inspector }\end{array}$ & 2 & $\begin{array}{l}\text { Responsible for site engineering } \\
\text { quality inspection }\end{array}$ \\
\hline Surveyors & 3 & $\begin{array}{l}\text { Responsible for tunnel survey and } \\
\text { monitoring }\end{array}$ \\
\hline $\begin{array}{l}\text { Security } \\
\text { officer }\end{array}$ & 2 & Responsible for site safety work \\
\hline $\begin{array}{l}\text { Excavation } \\
\text { workers }\end{array}$ & 24 & Responsible for tunnel excavation \\
\hline $\begin{array}{l}\text { Professional } \\
\text { driver }\end{array}$ & 6 & $\begin{array}{l}\text { Power Generation, Air } \\
\text { Compressor, Construction } \\
\text { Machinery }\end{array}$ \\
\hline Repairman & 2 & $\begin{array}{l}\text { Responsible for mechanical and } \\
\text { electrical maintenance }\end{array}$ \\
\hline $\begin{array}{l}\text { General } \\
\text { labourers }\end{array}$ & 2 & $\begin{array}{l}\text { Responsible for environmental } \\
\text { protection, hygiene and other } \\
\text { sundries on site }\end{array}$ \\
\hline
\end{tabular}

\subsection{Mechanical equipment}

Table2. Mechanical equipment.

\begin{tabular}{|c|c|c|c|}
\hline $\begin{array}{c}\text { Serial } \\
\text { number }\end{array}$ & Device name & $\begin{array}{c}\text { Specification } \\
\text { type }\end{array}$ & Quantity \\
\hline 1 & Loader & Liu Gong $3 \mathrm{~m}^{3}$ & 2 \\
\hline 2 & Excavator & $\begin{array}{c}\text { Xiao Song } \\
0.8 \mathrm{~m}^{3}\end{array}$ & 1 \\
\hline 3 & Alternator & $300 \mathrm{kw}$ & 2 \\
\hline 4 & $\begin{array}{c}\text { Pneumatic rock } \\
\text { drill }\end{array}$ & YT28 & 20 \\
\hline 5 & Air compressor & W-6/7 & 4 \\
\hline 6 & Water pump & $7.5 \mathrm{kw}$ & 3 \\
\hline 7 & Dump truck & $\begin{array}{l}\text { Hong Yan } \\
\text {-CQ30290 }\end{array}$ & 4 \\
\hline 8 & Ventilator & axial-flow & 1 \\
\hline
\end{tabular}

\section{Blasting scheme and technology}

After the completion of the entrance project, the blasting operation is carried out based on the type of surrounding rocks and lining under the premise of ensuring the safety of the hole.

After the completion of the side-and-face upward slope support, the position of the tunnel entrance is re-measured, and the contour of the anchor bolt and the excavation contour are drawn. The consolidation support is implemented in advance. After that, circular or benching tunnelling at the shallow section of the rock is conducted. The weak surrounding rock is manually excavated with the help of excavators, and the loosening blasting is adopted in the bedrock.

The III-level surrounding rock of Yazhugou Tunnel adopts full-section smooth blasting excavation method. Benching tunnelling is considered as an option at the entrance and the local area where the surrounding rock is quite weak and the self-stabilization time is short.

In order to deliver good blasting performance during construction, it is necessary to control the position of the surrounding blast-holes and the external angle. The size of the external angle directly affects the degree of over-under-break. If the angle is too big, then over-break occurs; if the angle is too small, then under-break occurs, leading to insufficient space for the next cycle.

\subsection{Selection of blasting parameters}

Smooth blasting is mainly related to geological conditions, followed by the variety and performance of the explosive, and the size and shape of the tunnel section.

The smooth blasting parameters of the Yazhugou Tunnel are determined based on the above factors.

The diameter of the blast-hole is $42 \mathrm{~mm}$, and that of the explosive cartridge is $32 \mathrm{~mm}$.

The distance between the section and arc peripheral blast-holes is set as $600 \mathrm{~mm}(\mathrm{a}=(12 \sim 20) \mathrm{db})$.

The minimum resistance line $\mathrm{W}=\mathrm{Q} \times \mathrm{C}{ }_{\mathrm{q}} \times \mathrm{a} \times \mathrm{L}$. Q: the charge amount of Blast hole; $\mathrm{C}_{\mathrm{q}}$ : blasting coefficient, equivalent to unit consumption. For $\mathrm{f}=4 \sim 10$ rock formation, $\mathrm{C}_{\mathrm{q}}$ varies from 0.2 to $0.5 / 3$; a: blast-hole spacing; L: blast-hole depth.

The minimum resistance line $\mathrm{W}$ is related to the nature of the rock and the geological structure. The hardness of the hard rock can be set as 500-600, and that of the soft rock, $800-900$ (600-700 for small-span tunnels).

Explosive play-load: $\mathrm{Q} \mathrm{c}=\mathrm{q} \times \mathrm{a} \times \mathrm{W} \times \mathrm{L}$. $\mathrm{q}$ : the unit explosive consumption determined by quota, $(\mathrm{kg} / \mathrm{m} 3)$; L: the average depth of the smooth surface blast-hole (m); a: blast-hole spacing; W: minimum resistance line.

Line charge density: $\mathrm{Q} \times \mathrm{L}=\mathrm{Q}_{\mathrm{c} \times \mathrm{L}}=\mathrm{q} \times \mathrm{a} \times \mathrm{W}$.

Non-coupling coefficient: $\mathrm{B}=1.5$ to 2.0 .

It is better to set blast-hole density coefficient as $\mathrm{m}=\mathrm{a}$ $/ \mathrm{W}=0.8 \sim 1.0$.

\subsection{Blasting equipment}

A handheld feed-leg YT-28 pneumatic rock drill with a slotted alloy broach $(\varphi=40 \mathrm{~mm})$ is used to drill the blast-holes. The explosive is made of $2 \#$ rock ammonium explosive or emulsion explosive with diameter of $32 \mathrm{~mm}$. This paper adopts plastic detonator and millisecond detonator detonation systems, and uses 17-section millisecond detonator in a light-flooding manner to avoid irregularity. 


\subsection{Slotting method}

The full-section blasting of III-level surrounding rock adopts double-hole straight slotting, while the excavation of IV-level surrounding rock adopts slanting wedge-shaped slotting.

\subsection{Drilling and blasting technology (taking V-level surrounding rock as an example)}

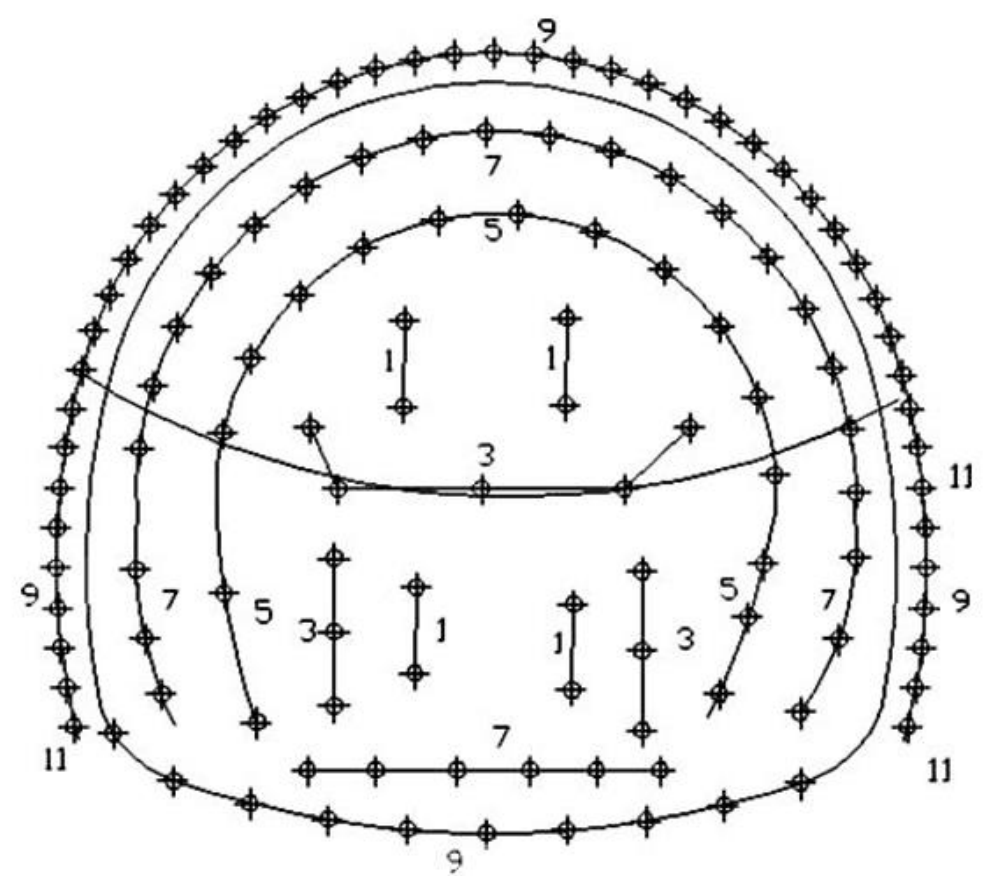

Figure1. Blast-hole layout.

Table3. Blasting parameters of the upper steps of V-level surrounding rock.

\begin{tabular}{|c|c|c|c|c|c|}
\hline Name & $\begin{array}{c}\text { Hole } \\
\text { depth }(m)\end{array}$ & Quantity & $\begin{array}{l}\text { Single hole } \\
\text { charge }(\mathrm{kg})\end{array}$ & $\begin{array}{c}\text { Millisecond segment } \\
\text { number }\end{array}$ & $\begin{array}{c}\text { Firing } \\
\text { sequence }\end{array}$ \\
\hline Cut-hole & 1.3 & 4 & 0.6 & 1 & 1 \\
\hline Auxiliary Holes & 1.1 & 5 & 0.5 & 3 & 2 \\
\hline Auxiliary Holes & 1.1 & 11 & 0.5 & 5 & 3 \\
\hline Auxiliary Holes & 1.1 & 16 & 0.5 & 7 & 4 \\
\hline $\begin{array}{l}\text { Perimeter } \\
\text { Blast-holes }\end{array}$ & 1.0 & 29 & 0.5 & 7 & 4 \\
\hline
\end{tabular}

Table4. Blasting parameters of the left and right sides (one side) of the lower steps of the V-level surrounding rock.

\begin{tabular}{lllllc}
\hline \multicolumn{1}{c}{ Name } & $\begin{array}{c}\text { Hole } \\
\text { depth }(\mathrm{m})\end{array}$ & Quantity & $\begin{array}{c}\text { Single hole } \\
\text { charge(kg) }\end{array}$ & $\begin{array}{c}\text { Millisecond } \\
\text { segment number }\end{array}$ & $\begin{array}{c}\text { Firing } \\
\text { sequence }\end{array}$ \\
\hline Cut-hole & 1.3 & 2 & 0.6 & 1 & 1 \\
Auxiliary Holes & 1.1 & 3 & 0.5 & 3 & 2 \\
Auxiliary Holes & 1.1 & 3 & 0.5 & 5 & 3 \\
Auxiliary Holes & 1.1 & 7 & 0.5 & 7 & 4 \\
Perimeter Blast-holes & 1.1 & 8 & 0.5 & 11 & 5 \\
Perimeter Blast-holes & 1.0 & 1 & 0.5 & 9 & 6 \\
Perimeter Blast-holes & 1.1 & 6 & 0.8 & & 7 \\
\hline
\end{tabular}




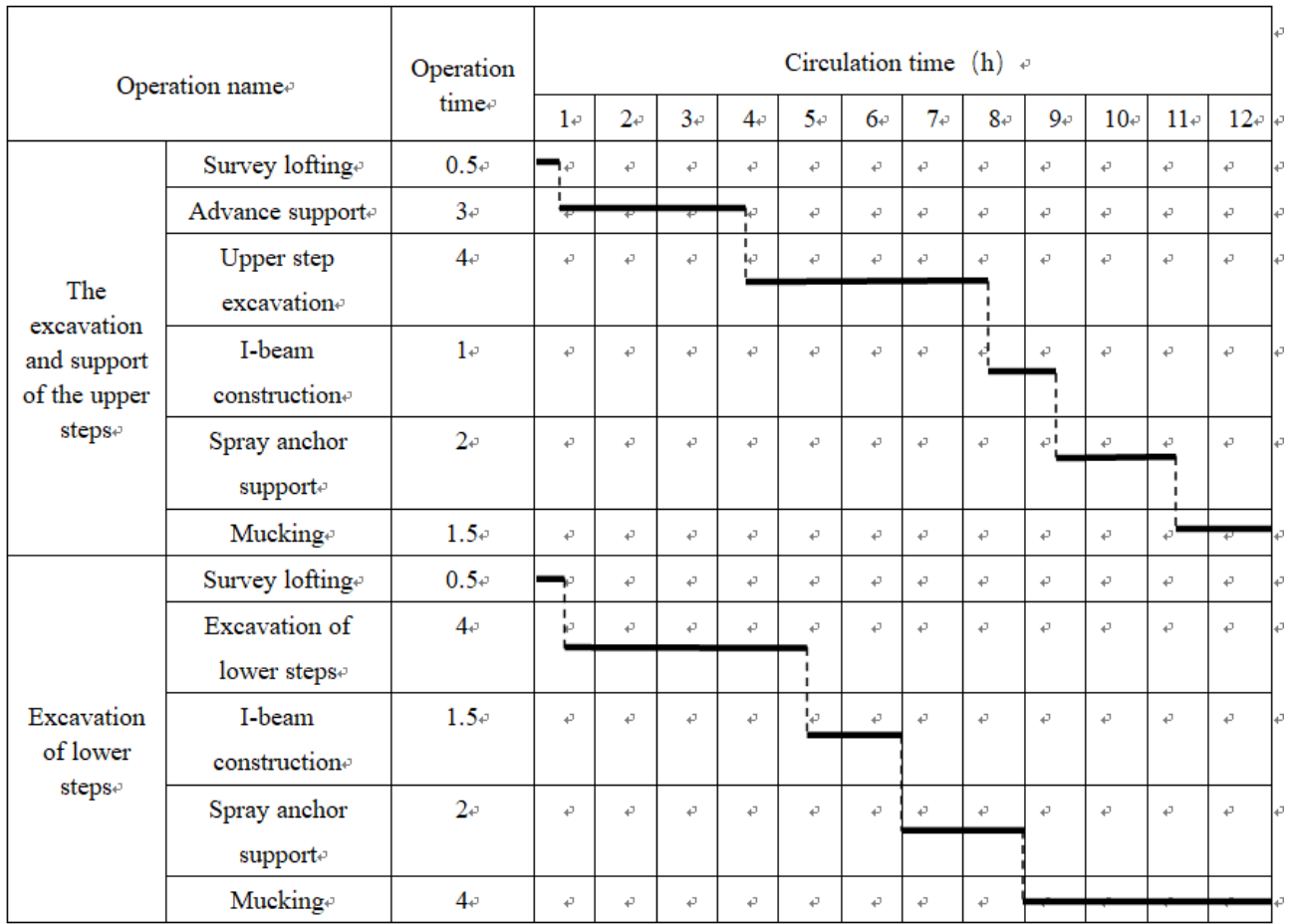

Figure2. Construction schedule of V-level surrounding rock.

\subsubsection{Drilling and charging}

In order to achieve a good blasting effect, the construction contour line is drawn by the measurement team using the total station before drilling, and the blast-holes are arranged by the field technical supervisor. The drilling position error shall meet the following standards: the bottom of peripheral blast-holes shall not exceed $15 \mathrm{~cm}$ of the excavation contour line; the error of the groove is not more than $5 \mathrm{~cm}$ per meter. The cause of the position deviation of holes is the deviation of the drilling direction and the unevenness of the rock and the lack of rigidity of the drill pipe.

Best blasting performance is guaranteed by reasonable charging and controlling explosive play-load and charge structure. Before charging, use high-pressure air hose to remove the residue and accumulated water in the blast-hole, and carefully check the various indicators, including position, angle and depth. Charging should be carried out strictly in accordance with the designed loading amount. When the surrounding rock and design strength change greatly, it is feasible to adjust according to the actual situation on site. The blast-hole blockage can be manually tamped in layers using clay.

\subsubsection{Detonation}

The detonation network must ensure that each cartridge detonates follow the designed detonation sequence and time. When using the detonating tube, it is a must to adopt the correct connection with no more than 15 detonating tubes in each series in series connection. Accurate detonation can rely on double detonating tubes, which also requires that all connected detonating tubes equipped with detonators or fire detonators are firmly connected.

\section{Guarantee measures}

\subsection{Technical quality assurance measures}

Give technical training to blasting operators, and develop blasting construction quality management and reward and punishment systems.

Improve the accuracy of the blast-hole layout. Before drilling, use the instrument to determine the central line, arch and road elevation, draw out the contour line, and use the coordinate method to calibrate the position of the blast-hole.

Improve tapping and drilling accuracy. When drilling the peripheral holes, make sure that the blast-hole is on the contour line, with proper depth, direction and external angle so as to ensure that the resistance line is consistent and position and the direction of the inner holes is strictly controlled. The drilling depth shall be strictly controlled to ensure the bottom of all kinds of blast-holes is on the same vertical surface, which is crucial to the flatness of post-explosion surface and the measurement and drilling operation of the next round.

Strictly control the charge amount of peripheral holes based on the air interval charge structure so as to increase the uncoupling coefficient and the buffering effect during blasting and reduce the damage to surrounding rock.

Adopt the reverse charge structure (i.e. the detonator is installed at the bottom of the blast-hole) in order to improve the utilization of blast-holes, strengthen rock fragmentation and reduce the bulk rate. Strictly control the order of detonation.

Perform blasting effect analysis timely, carry out excavation section inspection and information feedback, 
adjusting blasting parameters and construction measures according to specific conditions.

\subsection{Blasting safety measures}

In order to strengthen and standardize the safety management of engineering blasting, to prevent the loss and theft of blasting articles and blasting accidents, it is necessary to hold the persons who are in charge and those who use the object accountable. It is important to follow the principle of "active prevention, strict management, serve production, and guarantee safety".

All engineering blasting should be reported to the public security organization for approval before it can be performed.

Establish a safety production organization during construction with the full-time safety officer, a certain number of certified blasting technicians and the powder-man, security officer, custodian, and escort.

The blasting technicians and the powder-man, security officer, custodian, and escort shall be registered and reviewed annually; otherwise, they shall not engage in blasting operations.

The certificates for purchasing explosives and transporting of the blasting project approved by the public security organization shall be handled by the public security organization at or above the county level, and the name of the explosive used shall be indicated on the purchase certificate.

Before the blasting design and construction, it is a must to acquire Safety Operation Certificate for Blasting Engineering Technicians, Blaster Certificate, Security Officer Certificate, Custodian Certificate, Escort Certificate, Purchase Certificate and Transport Certificate.

The blasting equipment shall comply with the Blasting Safety Regulations, and the inventory and layout should be approved by the local public security organs.

The blasting items shall be managed by special personnel. They should be stored based on classification. The spacing between the detonators and the explosive warehouse, and that between the warehouses and the residential areas shall meet relevant regulations.
Strengthen supervision over the management, transport and usage of blasting items. The inventory should be verified and inspected every week. The whole process of using the blasting items should be supervised by the security officer to avoid hidden dangers.

\section{Conclusion}

Smooth blasting is widely used in tunnel construction. In application, the adjustment of the spacing, number, and length of the blast-holes and the charging amount according to different geological conditions has a great impact on the excavation speed, stability of surrounding rock, and over-under-break.

The successful application of smooth blasting in the road reconstruction in the hydropower station on the upper reaches of the Yalong River has achieved good economic results, providing reference for similar projects in the future.

\section{References}

1. Zhou, S. (2001) Road and bridge construction calculation manual. China Communications Press, Beijing.

2. Xu, W. (2018) Application of Smooth Blasting Construction Technology in Expressway Tunnel. Building Materials and Decoration, 16: 240-241.

3. Luo, M. (2018) Key Technology Analysis of Smooth Blasting Construction in Mountain Tunnel. Anhui Architecture, 47: 783-786.

4. Zhang, J.B. (2012) Research on Construction Technology of Deep Hole Groove Smooth Blasting in Large Section Hard Rock Tunnel. In: The 17th Annual Meeting of the 15th Annual Meeting of the China Civil Engineering Society and the Tunnel and Underground Engineering Branch. Kunming. pp. 430-433.

5. Yin, B. (2019) Application Analysis of Smooth Blasting Construction Technology for Expressway Tunnel. Value Engineering, 12: 99-101. 